\title{
Retraction Note to: Research on the relationship between seawater temperature changes and the start-up of characteristic towns in coastal cities based on spatial features
}

\author{
Jiaying $\mathrm{Xi}^{1} \cdot$ Honglin $\mathrm{Bao}^{2}$ \\ Published online: 15 November 2021 \\ (c) Saudi Society for Geosciences 2021
}

Retraction Note to: Arabian Journal of Geosciences (2021) 14: 1114 https://doi.org/10.1007/s12517-021-07403-w

The Editor-in-Chief and the Publisher have retracted this article because the content of this article is nonsensical. The peer review process was not carried out in accordance with the Publisher's peer review policy. The authors have not responded to correspondence regarding this retraction.

The original article can be found online at https://doi.org/10.1007/ s12517-021-07403-w.

\section{Jiaying Xi}

Xijiaying7890@163.com

1 Zhejiang Technical Institute of Economics, Hangzhou 310018, Zhejiang, China

2 Xiaoshan No. 1 Secondary Vocational School of Hangzhou in Zhejiang Province, Hangzhou 311200, Zhejiang, China 